\title{
ESPELHO INTELIGENTE COM INTERAÇÃO POR COMANDO DE VOZ.
} DOI 10.37619/issn2447-5378.v7i1.318.60-71

\author{
F.C. Santos ${ }^{1, *}$; W.S. Parra ${ }^{1}$; S.M. Lugones ${ }^{1}$ \\ 1 Faculdade de Tecnologia de São José dos Campos - Professor Jessen Vidal \\ Av. Cesare Mansueto Giulio Lattes, 1350 - Eugênio de Melo, São José dos Campos/SP, \\ CEP.: 12247-014, Brasil.
}

Telefone: (12) 3905-2423

*fabricio.santos38@fatec.sp.gov.br

\begin{abstract}
RESUMO: No mundo atual há uma grande quantidade de informações sendo jogados à nossa frente a todo tempo, sendo as telas dos celulares e dos aparelhos conectados à rede de propagandas e de acesso a informações corriqueiras ou triviais. Com a evolução da Internet das Coisas (IoT), surgem muitas inovações como também a necessidade de estar conectado o tempo todo. Este artigo apresenta uma solução tecnológica capaz de facilitar o acesso a informações rápidas e atualizadas enquanto se faz outras tarefas à frente de um espelho. Nesta solução encontra-se um dispositivo que fornece vários conteúdos informativos como horas, meteorologia, notícias, tabela de jogos esportivos etc. O método consiste em um vidro refletivo acoplado a um monitor e um minicomputador Raspberry Pi gerenciados por qualquer dispositivo Alexa.
\end{abstract}

PALAVRAS-CHAVE: Internet das Coisas; Espelho Inteligente; Espelho com Alexa.

ABSTRACT: In the current world there is a large amount of information being thrown in front of us at all times like screens of cell phones and devices connected to the network of advertisings and access to common or trivial information. With the evolution of the Internet of Things (IoT) there are many innovations and also a need to be connected all the time. This article introduces a technological solution capable to facilitate access to fast and updated information while doing other tasks in front of a mirror. In this solution there is a device that offers many information contents such as hours, weather, news, sports games table, etc. The method consists of a reflective glass attached to a monitor and a Raspberry Pi minicomputer managed by any Alexa device.

KEYWORDS: Internet of Things; Magic Mirror; Alexa's Mirror.

\section{INTRODUÇÃO}

Este trabalho tem como objetivo trazer ao mercado nacional e aos olhos dos consumidores a necessidade de se manter sempre atualizado, substituir tecnologias obsoletas e inovar ganhando espaço e praticidade.

"Os espelhos ainda são pouco utilizados como base para projetos de internet das coisas. Entretanto, já existem alguns trabalhos que apresentam funcionalidades para eles além da simples reflexão do usuário" (SILVA; VIALICH, 2017). A ideia que inspira a trazer este projeto à nossa realidade, é o MagicMirror ${ }^{2}$ criada por Michael Teeuw a plataforma utilizada para este projeto.

"Algumas das tarefas que maior parte das pessoas faz no decorrer do seu dia-a-dia é ler notícias, ver a meteorologia, usar o espelho para a sua higiene pessoal, entre muitas outras" (ESCUDEIRO, 2019). A ideia é deixar de uma forma prática e otimizar o tempo do utilizador realizando estas atividades enquanto se arruma diante do espelho.

Os desafios encontrados durante o projeto foram os de conseguir uma forma de baixo custo para facilitar a projeção das ideias em algo físico e conseguir trazer ao mercado nacional o conceito 


\section{ISSN $2447-5378$}

MagicMirror, sem a necessidade de importar todos os materiais necessários para a construção do espelho, havendo apenas a necessidade de realizar adaptações e outras opções de matéria-prima. $\mathrm{O}$ protótipo atual tem como principal objetivo confirmar e analisar a substituição do acrílico espelhado (a principal matéria prima usada em outros projetos) e que só é encontrada em outros países norteamericanos, tendo um custo muito elevado além do risco de transporte na importação de uma peça frágil.

\section{REVISÃO BIBLIOGRÁFICA}

\subsection{Internet das Coisas (IOT)}

Utilizado pela primeira vez em 1999 por Kevin Ashton um pesquisador britânico que veio posteriormente ser conhecido como o criador do "Internet das Coisas" (Internet of Things), se refere a uma revolução tecnológica que seu objetivo é conectar coisas do cotidiano à rede mundial de computadores. Cada vez mais surgem meios de transporte, eletrodomésticos, maçanetas, sistemas de segurança conectados à computadores e smartphones. A ideia é que cada vez mais o mundo físico e o mundo digital tornem-se um só (BRASIL, 2015).

"A Internet das Coisas (IOT) é a rede de dispositivos e, em geral, as coisas que estão conectadas e se comunicam entre si para determinadas tarefas, sem exigir interação entre humanos ou entre seres humanos" (SANTOS, 2018, p.29).

\subsection{Assistente Virtual}

Um assistente pessoal inteligente é um agente de software que pode realizar tarefas ou serviços para um indivíduo. Estas tarefas ou serviços são baseados na entrada do usuário, geolocalização, e a capacidade de acessar informações de uma variedade de fontes on-line, tais como condições meteorológicas e de trânsito, notícias, os preços das ações, horários de usuários, entre outros. Exemplos de assistentes virtuais inteligentes são a Siri, Google Assistent e Microsoft Cortana.

O nome deve-se à capacidade que ele tem de fornecer assistência em uma série de ações, como fazer pesquisas usando o buscador do Google, abrir aplicativos, ouvir música, ver fotos e vídeos, gerenciar compromissos na agenda, enviar e-mails, ou simplesmente fazer perguntas sobre uma série de questões que se tenha dúvidas, bastando para isso que você fale o que deseja fazer e ele literalmente reconhece a sua fala e interpreta o que você deseja. (HOSTMIDIA, 2019)

\section{MATERIAIS E MÉTODOS}

\subsection{Magic Mirror ${ }^{2}$}

"MagicMirror" é uma plataforma de espelho inteligente modular de código aberto. Com uma lista crescente de módulos instaláveis, o MagicMirror ${ }^{2}$ permite que você converta seu espelho de corredor ou banheiro em seu assistente pessoal. MagicMirror ${ }^{2}$ foi construído pelo criador do MagicMirror original com a incrível ajuda de uma comunidade crescente de colaboradores.

MagicMirror ${ }^{2}$ concentra-se em um sistema modular de plugins e usa Electron como um wrapper de aplicativo" (MAGICMIRROR², 2020).

\subsection{Electron}


"MagicMirror" Electron, antes conhecido como Atom Shell foi desenvolvido com Chromium e Node.js, ele é um framework utilizado para criar aplicações multiplataformas desktop com tecnologias como JavaScript e CSS" (THDESENVOLVEDORES, 2017).

\subsection{Raspberry Pi}

"Raspberry Pi é um computador de baixo custo criado com propostas educativas. Utiliza o Linux e seus softwares são gratuitos, em sua maioria. Há softwares para visualização de imagens no formato DICOM. Com o uso de um monitor externo, a resolução suportada $(1920 \times 1200$ pixels $)$ permite a criação de estações de visualização simples de exames com custo reduzido" (PAIVA; MOREIRA, 2013).

\subsection{Raspberry Pi OS (Raspibian)}

"Anteriormente chamado de Raspbian, o Raspberry PI OS é o sistema operacional oficial com suporte da Fundação. O sistema operacional Raspberry Pi vem pré-instalado com diversos softwares para educação, programação e uso geral. Possui Python, Scratch, Sonic Pi, Java e muito mais" (RASPBERRY, 2020).

\subsection{Módulos Utilizados}

Os módulos utilizados no presente trabalho estão à disposição na página de módulos no site do projeto Magic Mirror ${ }^{2}$ aba modules (PARTY MODULES, 2020).

Todos os módulos citados na Tabela 1 foram feitas adaptações para se adequar ao nosso protótipo, sendo elas, desenvolvimento de arquivo .css para alteração visual e/ou algumas configurações de personalização.

Tabela1. Módulos utilizados como base do protótipo.

\begin{tabular}{|c|c|c|c|c|}
\hline Nome & Autor & Descrição & Nativo & Adaptação \\
\hline Clock & MithMith & $\begin{array}{c}\text { O módulo de relógio é um dos módulos } \\
\text { padrão do MagicMirror. Este módulo } \\
\text { exibe a data e hora atuais. As } \\
\text { informações serão atualizadas em } \\
\text { tempo real. }\end{array}$ & Sim & $\begin{array}{l}\text { Ajusta automaticamente } \\
\text { com a hora do Raspberry }\end{array}$ \\
\hline Calendar & MithMith & $\begin{array}{l}\text { O módulo de calendário é um dos } \\
\text { módulos padrão do MagicMirror. Este } \\
\text { módulo exibe eventos de um calendário } \\
\text { público. Ele pode combinar vários } \\
\text { calendários. }\end{array}$ & Sim & $\begin{array}{l}\text { Configurado para retirar } \\
\text { arquivo ics de acordo } \\
\text { com site } \\
\text { http://www.supercalenda } \\
\text { rio.com.br }\end{array}$ \\
\hline $\begin{array}{l}\text { Current } \\
\text { Weather }\end{array}$ & MithMith & $\begin{array}{c}\text { O módulo currentweather é um dos } \\
\text { módulos padrão do MagicMirror. Este } \\
\text { módulo exibe o clima atual, incluindo a } \\
\text { velocidade do vento, o pôr do sol ou } \\
\text { hora do nascer do sol, a temperatura e } \\
\text { um ícone para exibir as condições } \\
\text { atuais. }\end{array}$ & Sim & $\begin{array}{c}\text { Configurado as } \\
\text { informações de ID da } \\
\text { cidade de acordo com o } \\
\text { site } \\
\text { http://bulk.openweatherm } \\
\text { ap.org/sample/city.list.jso } \\
\text { n.gz }\end{array}$ \\
\hline
\end{tabular}




\begin{tabular}{|c|c|c|c|c|}
\hline News Feed & MithMith & $\begin{array}{l}\text { O módulo newsfeed é um dos módulos } \\
\text { padrão do MagicMirror. Este módulo } \\
\text { exibe manchetes de notícias com base } \\
\text { em um feed RSS. A rolagem pelas } \\
\text { manchetes das notícias acontece com } \\
\text { base no tempo (updateInterval), mas } \\
\text { também pode ser controlada enviando } \\
\text { notificações específicas do feed de } \\
\text { notícias para o módulo. }\end{array}$ & Sim & $\begin{array}{l}\text { O módulo foi duplicado } \\
\text { no diretório para que } \\
\text { rode em duas instancias } \\
\text { sendo possível a adição } \\
\text { de diferentes sites em } \\
\text { páginas diferentes }\end{array}$ \\
\hline $\begin{array}{l}\text { Weather } \\
\text { Forecast }\end{array}$ & MithMith & $\begin{array}{c}\text { O módulo weatherforecast é um dos } \\
\text { módulos padrão do MagicMirror. Este } \\
\text { módulo exibe a previsão do tempo para } \\
\text { a próxima semana, incluindo um ícone } \\
\text { para exibir as condições atuais, a } \\
\text { temperatura mínima e a temperatura } \\
\text { máxima. }\end{array}$ & Sim & $\begin{array}{c}\text { Configurado as } \\
\text { informações de ID da } \\
\text { cidade de acordo com o } \\
\text { site } \\
\text { http://bulk.openweatherm } \\
\text { ap.org/sample/city.list.jso } \\
\text { n.gz }\end{array}$ \\
\hline $\begin{array}{c}\text { MMM- } \\
\text { AlexaOnOff }\end{array}$ & JoChef2 & $\begin{array}{l}\text { O módulo MMM-AlexaControl permite } \\
\text { que você controle seu espelho com } \\
\text { Alexa (todos os dispositivos que } \\
\text { suportam dispositivos Wemos). Você } \\
\text { pode ligá-lo e desligá-lo, mudar a } \\
\text { página e enviar notificações para outros } \\
\text { módulos. }\end{array}$ & Não & $\begin{array}{l}\text { Adicionado os nomes dos } \\
\text { comandos que serão } \\
\text { reconhecidos pela } \\
\text { assistente Alexa como } \\
\text { dispositivos na rede }\end{array}$ \\
\hline $\begin{array}{c}\text { MMM- } \\
\text { MyStandings }\end{array}$ & vincep5 & $\begin{array}{c}\text { Exibir a classificação da ESPN para as } \\
\text { principais ligas esportivas dos EUA e } \\
\text { internacionais de futebol }\end{array}$ & Não & $\begin{array}{l}\text { Configurado para } \\
\text { mostrar os campeonatos } \\
\text { específicos como NBA e } \\
\text { campeonatos brasileiros. }\end{array}$ \\
\hline $\begin{array}{c}\text { MMM- } \\
\text { MyScoreboar } \\
\text { d }\end{array}$ & jclarke 000 & $\begin{array}{l}\text { Módulo para MagicMirror para exibir } \\
\text { as pontuações de hoje de seus times } \\
\text { favoritos em vários esportes. }\end{array}$ & Não & $\begin{array}{c}\text { Configurado para } \\
\text { mostrar os campeonatos } \\
\text { específicos como NBA e } \\
\text { campeonatos brasileiros. }\end{array}$ \\
\hline $\begin{array}{l}\text { MMM- } \\
\text { NowPlayingO } \\
\text { nSpotify }\end{array}$ & raywo & $\begin{array}{c}\text { Exiba a música que você está ouvindo } \\
\text { no Spotify. }\end{array}$ & Não & $\begin{array}{l}\text { Configurado e inserindo } \\
\text { número ID Developer do } \\
\text { usuário spotify para a } \\
\text { funcionalidade, e } \\
\text { adicionado um novo } \\
\text { arquivo CSS } \\
\text { modificando o visual } \\
\text { para que fique mais } \\
\text { prático }\end{array}$ \\
\hline MMM-pages & $\begin{array}{l}\text { edward- } \\
\text { shen }\end{array}$ & $\begin{array}{l}\text { Um módulo mantido que permite que } \\
\text { você gire páginas de módulos! }\end{array}$ & Não & $\begin{array}{l}\text { Configuração básica } \\
\text { apenas informando quais } \\
\text { módulos serão visíveis } \\
\text { por página. }\end{array}$ \\
\hline
\end{tabular}


MMM-pageindicator
Um módulo auxiliar para exibir em qual edward- página você está. Destina-se a ser usado shen com outros módulos que giram para fora dos módulos.
Configuração básica apenas informando o número de páginas desejado.

\subsection{Assistente Virtual (Alexa)}

A Alexa é o serviço de voz baseado em nuvem da Amazon disponível em dezenas de milhões de dispositivos da Amazon e de fabricantes de dispositivos de terceiros. Com a Alexa, você pode criar experiências de voz naturais que oferecem aos clientes uma maneira mais intuitiva de interagir com a tecnologia que eles usam todos os dias (AMAZON ALEXA, 2020).

A ativação da Alexa é diferente dependendo do tipo de produto com a Alexa integrado. Em dispositivos de campo remoto com Alexa integrado, como Amazon Echo ou o Echo Dot, você pode ativar a Alexa pronunciando a palavra de ativação ou pressionando o botão "Ação", localizado na parte superior do dispositivo (ALEXANDER, 2018, p.4).

\subsection{Fluxo de Informações}

Ao utilizar a assistente virtual Alexa para que esta interaja com o espelho inteligente e traga as informações solicitadas é necessário que se tenha total acesso a rede wifi para configurar os dispositivos que tenham integrado a assistente virtual que utiliza do protocolo UPnP para funcionamento básico e possa se comunicar com outros dispositivos da rede.

A interação se faz por meio da configuração do módulo MMM-AlexaControl que nos permite atribuir IP's a determinadas linhas de comando sendo possível adicioná-las a assistente virtual como dispositivos, e assim que for solicitado a Alexa é disparado um comando de on/off para este determinado IP. Para otimização do processo citado foi criado uma rotina dentro do aplicativo Amazon Alexa para que substitua a frase "Alexa, ligar ..." apenas para "Alexa, ir para...".

O utilizador solicitará por voz as informações desejadas a assistente virtual, e esta informação será rapidamente enviada e processada através da rede para o dispositivo Raspberry Pi (Figura 1) no qual transmite as informações para o monitor localizado atrás do vidro refletivo retornando ao utilizador a ação desejada.

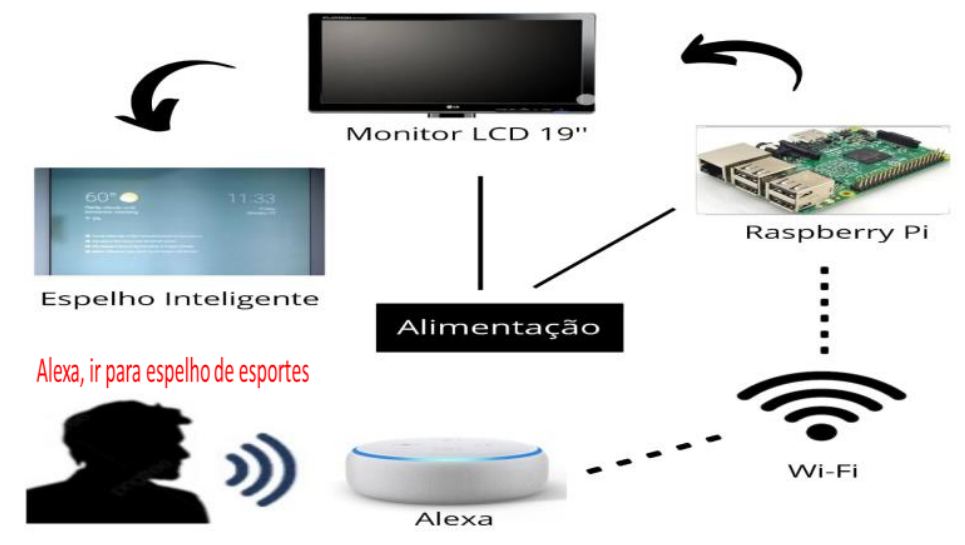

Figura 1. Fluxo de informações utilizando a assistente virtual. 


\title{
3.8. Patentes
}

\begin{abstract}
Patente é um título de propriedade temporária sobre uma invenção ou modelo de utilidade, outorgado pelo Estado aos inventores ou autores ou outras pessoas físicas ou jurídicas detentoras de direitos sobre a criação. Com este direito, o inventor ou o detentor da patente tem o direito de impedir terceiros, sem o seu consentimento, de produzir, usar, colocar a venda, vender ou importar produto objeto de sua patente e/ ou processo ou produto obtido diretamente por processo por ele patenteado. Em contrapartida, o inventor se obriga a revelar detalhadamente todo o conteúdo técnico da matéria protegida pela patente (PATENTES, 2020).
\end{abstract}

Ao se ter uma visão mais detalhada do mercado a ser inserido os produtos deste trabalho, foi feito uma pesquisa por patentes de produtos semelhantes para agregar ao projeto e deixar claro as diferenças dos outros produtos no mercado.

As gigantescas empresas Amazon e Samsung, mesmo sendo de mercados diferentes tem investido no mesmo conceito de smart mirror, e trazem algumas ideias de diferentes modelos para os consumidores.

A patente da Amazon tem a visão que permite o usuário experimentar roupas sem que seja se necessário esta real interação, fazendo um scan da área e criando um ambiente virtual para que seja possível a interação com várias dimensões na imagem projetada, sendo possível aprovar a satisfação da aquisição antes de compra-la (AMAZON, 2018).

"A patente da Samsung propõe a ideia de uma televisão que atua como espelho inteligente após ser desligada, mostrando informações como hora e previsão do tempo" (SAMSUNG, 2018).

A Samsung já atua no mercado de produtos de decoração e mistura seus aparelhos televisores a aparelhos do cotidiano, enfatizando no nome de seu produto "Smart Mirror TV" e que sua concorrência se trata ainda do mercado de televisores.

$\mathrm{Na}$ CES 2019 também foram apresentados alguns modelos de espelhos inteligentes como Capstone Connected Home, que vem com tela touch e Google Assistente integrado para utilizar dos comandos de voz.

Enquanto a arquitetura destas patentes utiliza de aplicações próprias e de código exclusivo tendo como o principal foco as características mencionadas anteriormente, o presente trabalho usa de inspiração as patentes citadas e utiliza da aplicação Magic Mirror ${ }^{2}$ como base para este protótipo, que tem seu código aberto não deixando o utilizador preso apenas a uma fonte de informação, podendo entrar em seu código e alterar por exemplo para a fonte de notícias desejada.

\subsection{Desenvolvimento}

As inovações sempre surgem com a finalidade de facilitar a vida cotidiana das pessoas, mesmo que elas ainda não saibam que necessitem destas facilidades em suas vidas, e a partir disto a implementação do conceito de "Internet das Coisas" tem ganhado força com o engrandecimento do termo Industria 4.0. Pensando em otimizar o tempo das pessoas que a cada dia se torna mais escasso, muitas possibilidades se abrem para um mercado que está em constante evolução, o presente trabalho apresenta a utilização de um espelho inteligente, em tarefas simples, como por exemplo, ver a previsão do tempo enquanto se arruma para ir ao trabalho ou ver as notícias atuais.

\subsubsection{Parte Lógica}

Utilizando de um mini computador Raspberry Pi, foi instalado em um cartão micro SD (16Gb) o sistema "Raspberry PI OS (32 bits) com desktop" e ao subir o sistema é instalado a aplicação Magic 


\section{ISSN $2447-5378$}

Mirror ${ }^{2}$, que foi utilizado como estrutura lógica para nosso protótipo, sendo feitas algumas configurações (Figura 2) para atender as necessidades dos utilizadores no Brasil, como por exemplo configurando o modulo nativo de feed de portais de notícias nacionais para ter as informações do cotidiano em português brasileiro (Figura 3). Foram adicionados módulos esportivos nacionais para que pudesse entregar o placar de jogos em tempo real, tabela esportiva de campeonatos brasileiros e o campeonato de basquete americano (Figura 4).
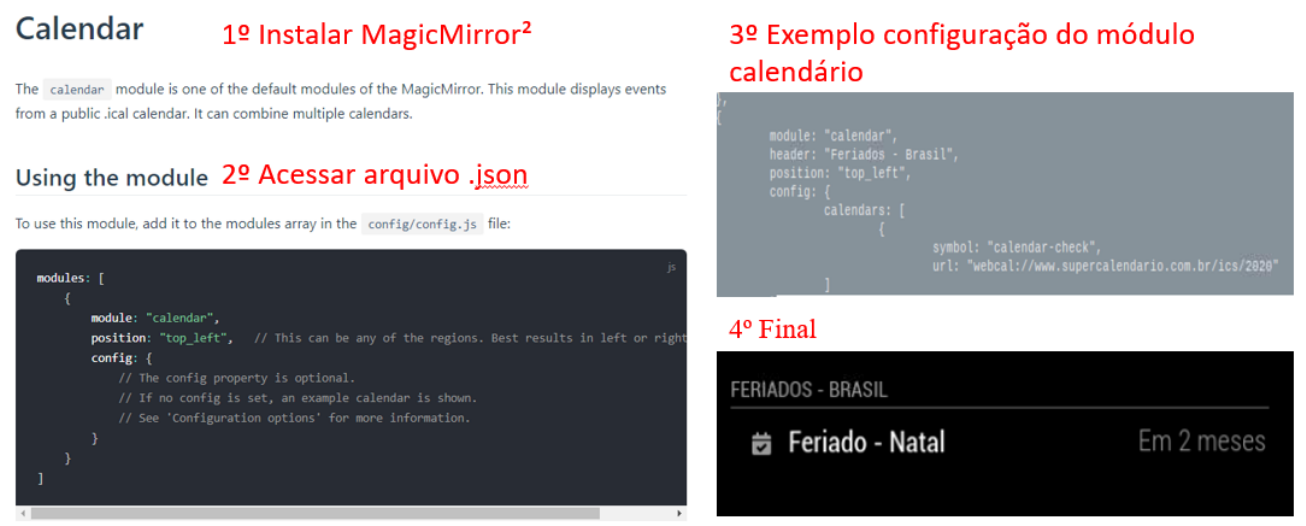

Figura 2. Exemplo de configuração de módulo nativo.

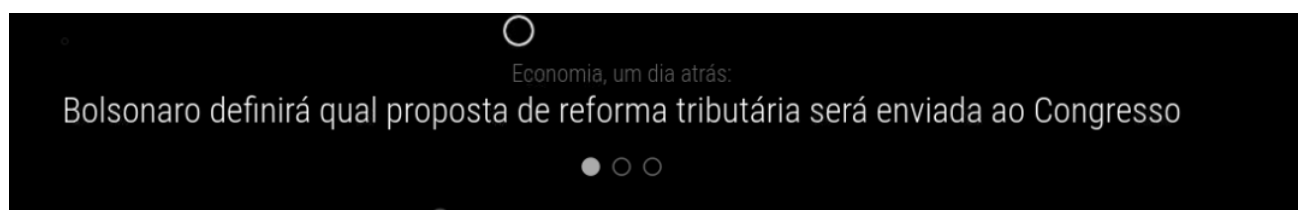

Figura 3. Feed de Notícias.

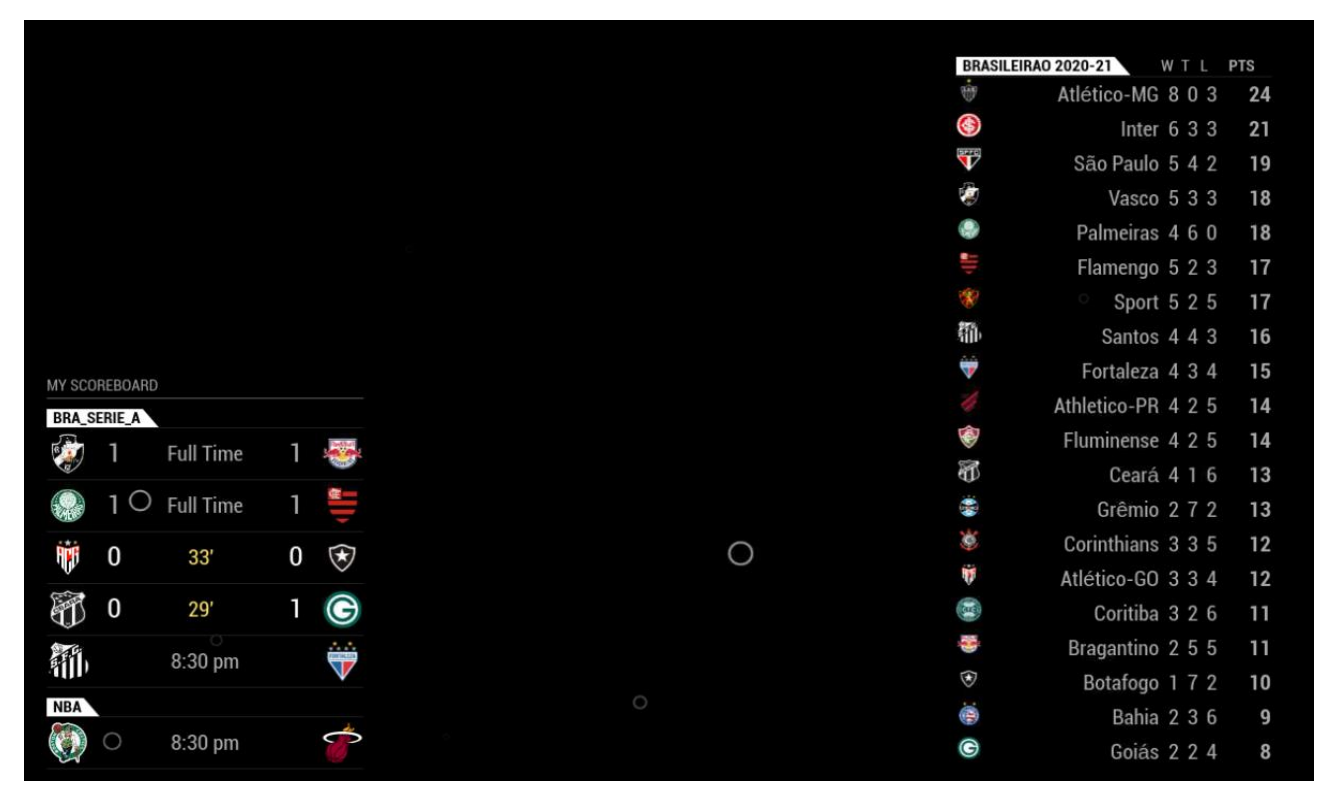

Figura 4. Painel de Esportes.

Foram atualizadas as informações de feriados para que mostrassem as datas comemorativas nacionais, e a previsão do tempo para que mostrasse as informações da região do utilizador (Imagem 


\section{ISSN $2447-5378$}

5). Por último foi adicionado módulo que integrasse o espelho ao Spotify e a assistente Alexa. (Imagem 6).

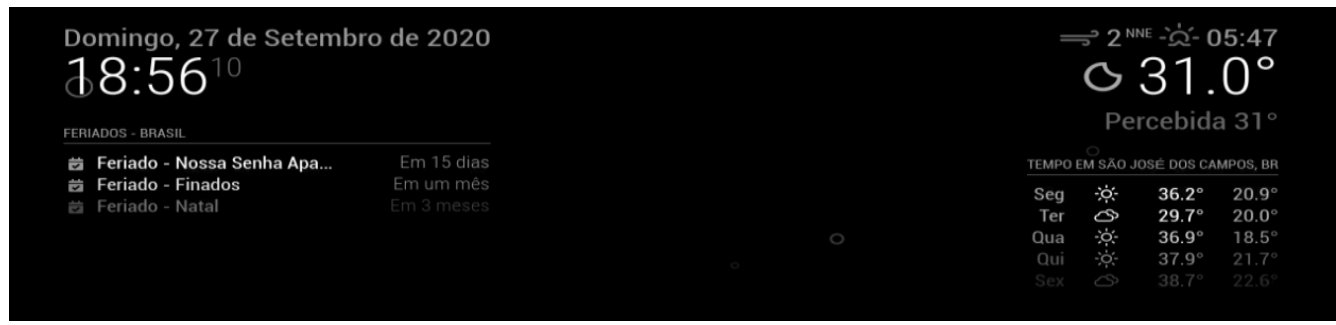

Figura 5. Painéis de Feriados e previsão do tempo.

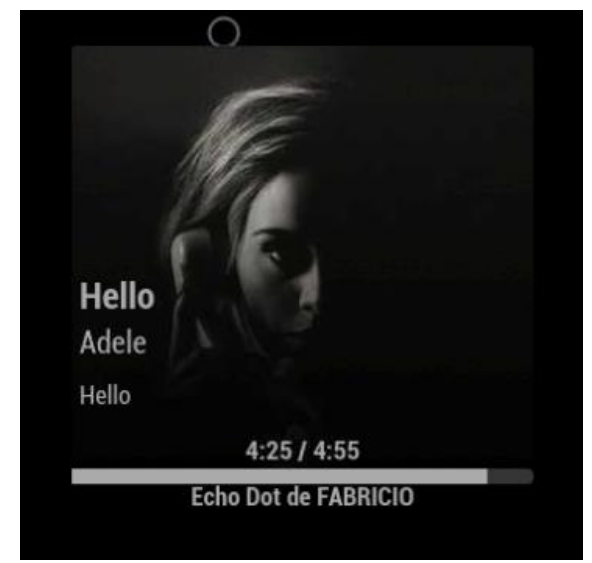

Figura 6. O que está tocando no Spotify.

\subsubsection{Estrutura Física}

Para melhor proteção das partes eletrônicas, principalmente da tela realizamos a construção da estrutura utilizando ripas de madeira, que após a construção certificamos de não ser a melhor escolha pelo seu peso ser muito elevado, porém seguimos com o processo.

A parte refletiva seguindo a adaptação que sugerimos de não utilizar os materiais importados que são de alto custo e muito menos o insulfilm refletivo como o já utilizado em outros projetos, optamos pela busca no mercado de vidros e encontramos o vidro reflecta na cor champagne que após os testes verificamos que o mesmo entrega o resultado desejado. Posicionamos o Raspberry pi (Figura 7), o monitor (Figura 8) e as demais peças como as fitas de led nas laterais para maior luminosidade em utilizações mais específicas como para fazer maquiagens.

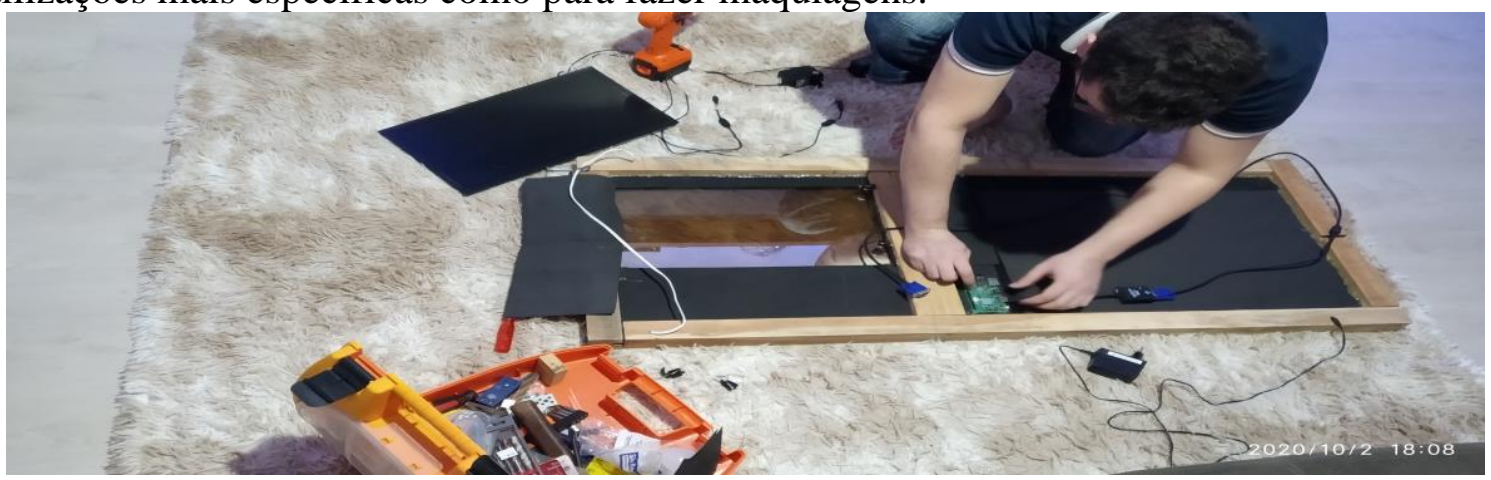

Figura 7. Posicionando Raspberry Pi e fiação na estrutura. 


\section{Congress of Industrial Management and Aeronautical Technology \\ Technology}

ISSN $2447-5378$

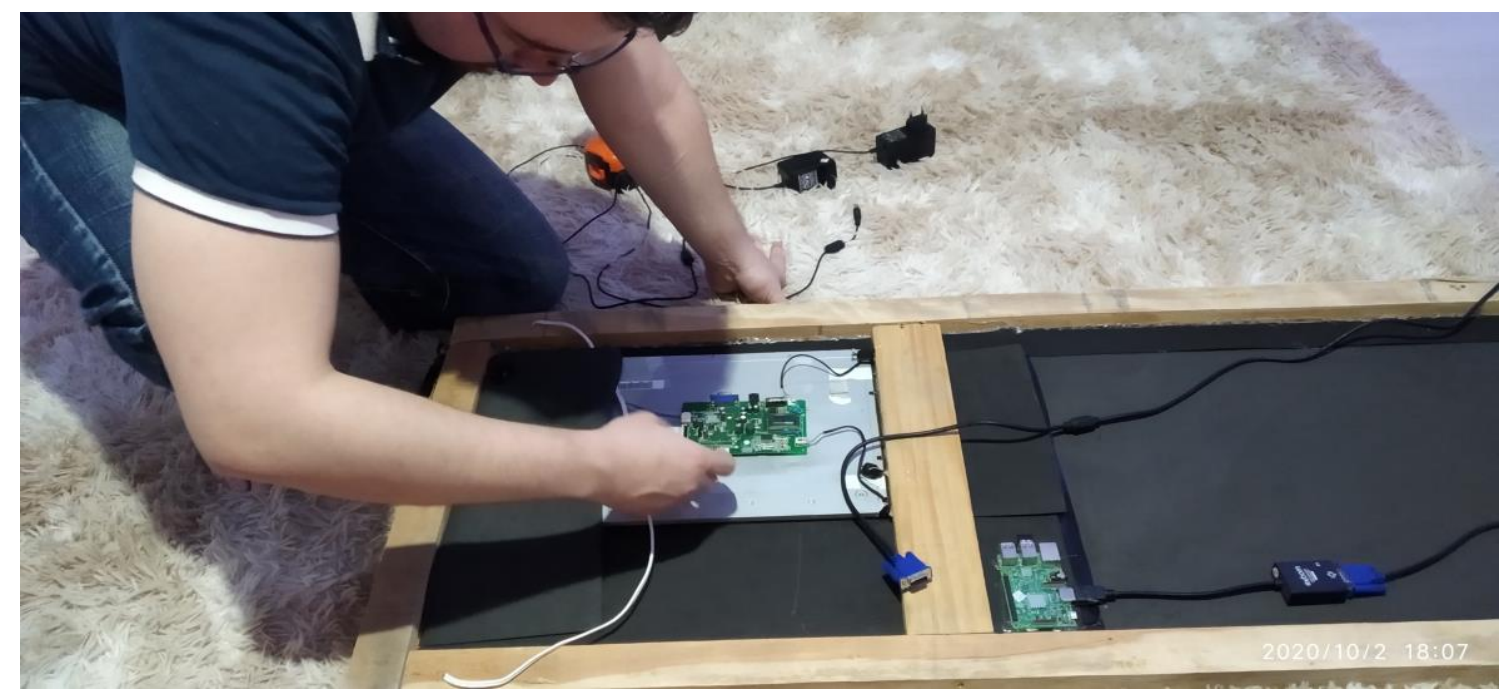

Figura 8. Posicionando o monitor.

Após a conclusão da montagem foram realizados os testes de segurança e desempenho do conjunto e verificamos o funcionamento e os resultados obtidos.

\section{RESULTADOS E DISCUSSÃO}

Utilizados apenas materiais de baixo custo e equipamentos que já haviam sido obtidos anteriormente trazendo a este conjunto um alto valor agregado, e desenvolvendo uma tecnologia antes pouco vista e que muitas vezes está ainda na imaginação das pessoas.

Os resultados obtidos apresentaram-se amplamente satisfatórios, sendo testados com diferentes timbres de voz, podendo ser utilizados por crianças e adultos, levando em consideração a ser apenas um projeto piloto de baixo custo (Figura 9). Foram utilizados alguns equipamentos reaproveitados e os que não obtínhamos compramos online, além de que encontramos fornecedores locais para atender tal necessidade nas medidas requeridas para a solução proposta do vidro refletivo, substituindo o acrílico espelhado (Figura 10). Em contato com o fabricante do vidro utilizado, foi informado que o produto suporta a variações de temperaturas de uma face para outra por volta de $200^{\circ}$ a $300^{\circ} \mathrm{C}$, sendo totalmente seguro para este protótipo, pois as maiores temperaturas foram registradas próximo ao processador do Raspberry Pi com uma temperatura máxima de $57^{\circ} \mathrm{C}$.

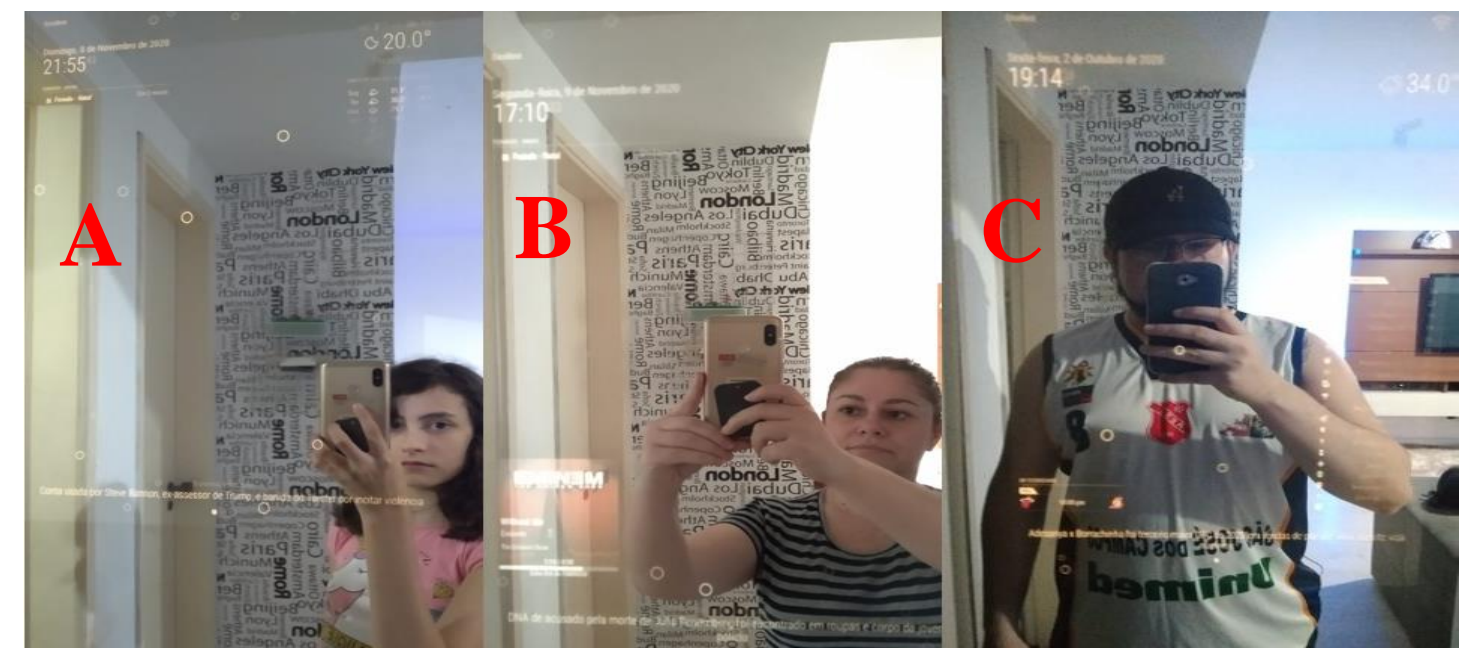

Figura 9. Testes de voz realizados em diferentes timbres de voz. 


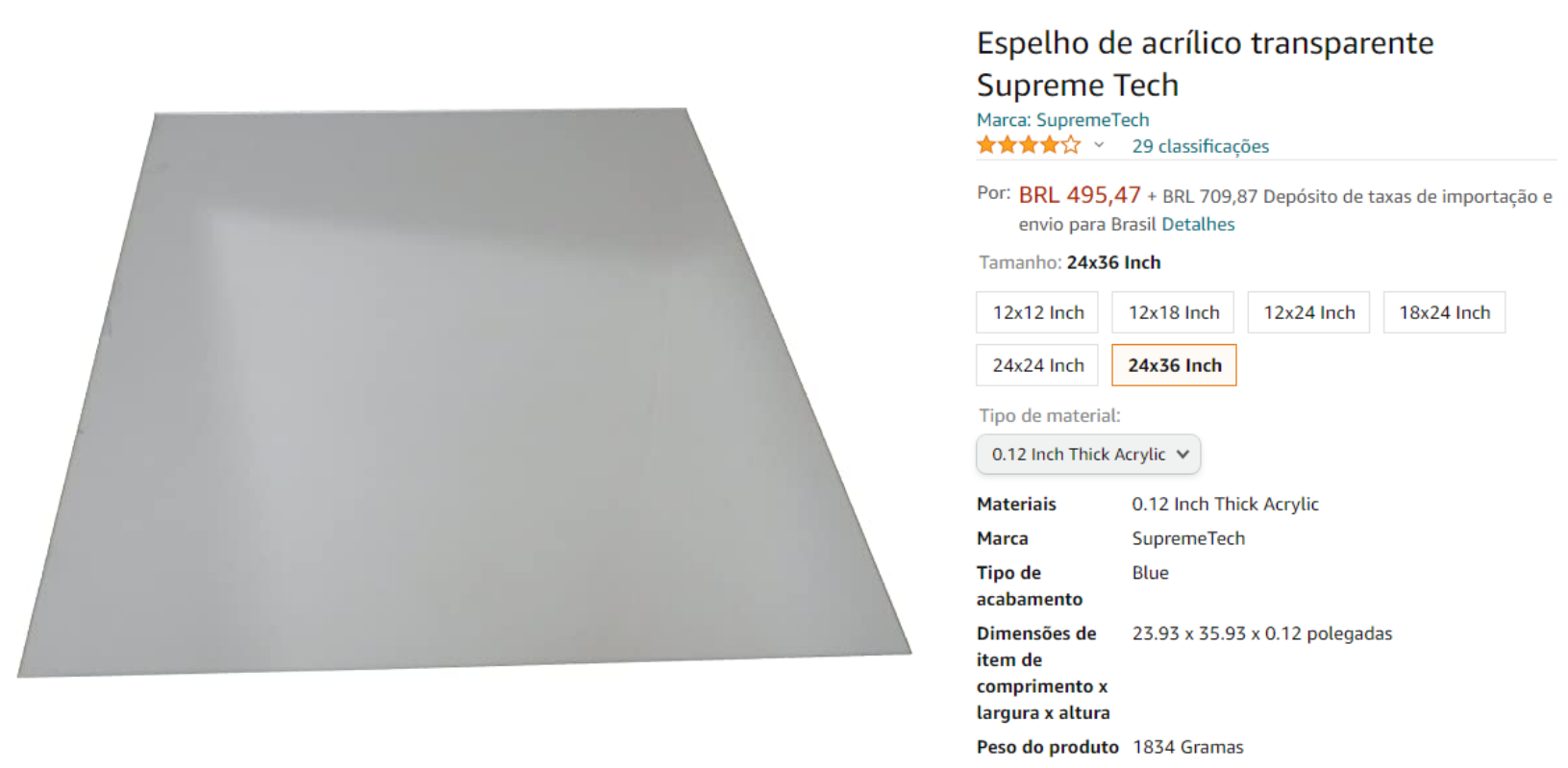

Figura 10. Custo do acrílico espelhado importado pela Amazon.

Um dos problemas encontrados foi o fato de cada componente utilizado ter uma fonte individual (Figura 11), para a unificação das fontes será necessário utilizar de reguladores de tensão linear. Ao pesquisar encontramos a família de circuitos integrados de reguladores de tensão "78xx" que torna o circuito seguro, controlando as saídas de corrente para cada dispositivo. Para este projeto piloto não foi implantado esta solução, mas está em desenvolvimento para aplicações futuras.

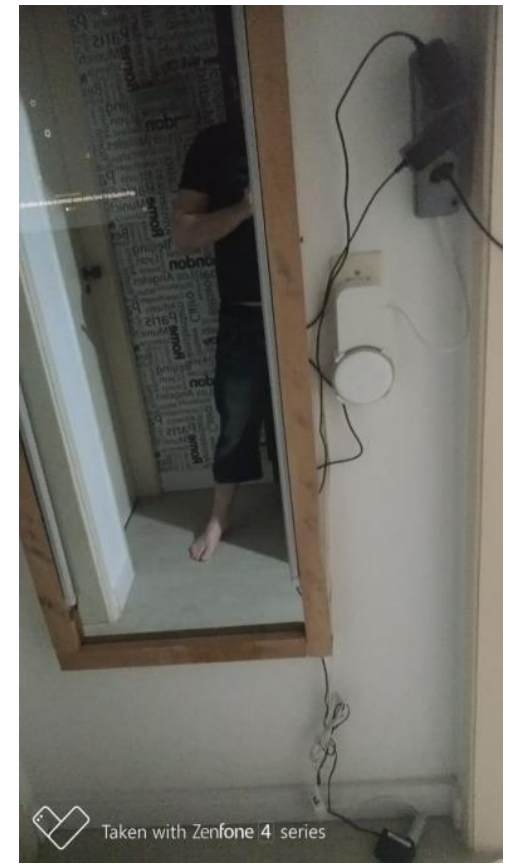

Figura 11. Resultado do espelho na página de esportes. 


\section{CONCLUSÃO}

O objetivo deste trabalho foi de estruturar o espelho inteligente com a maior quantidade de produtos nacionais para que seja viável a construção de um protótipo acadêmico/tecnológico.

Apesar das dificuldades enfrentadas conseguimos atingir o objetivo geral do trabalho que é o funcionamento do projeto piloto com a utilização por comandos de voz associados a um dispositivo com a assistente Alexa. Foram deixados para projetos futuros a consolidação das fontes para uma única peça que atenda ao produto como um todo, e a utilização de uma estrutura mais leve para diminuir riscos para o usuário.

Portanto pode-se afirmar que é totalmente viável a utilização do vidro espelhado encontrado no mercado nacional, trazendo um resultado totalmente satisfatório e de alto nível, além de reduzir o custo com este item em R\$1.075,44 conforme Tabela 2.

Tabela2. Comparação de custo entre as soluções refletivas.

\begin{tabular}{ccc} 
& Solução Original Magic Mirror & Solução Proposta \\
\hline Preço & $\mathrm{R} \$ 495,47$ & $\mathrm{R} \$ 129,90$ \\
Envio & $\mathrm{R} \$ 108,69$ & $\mathrm{R} \$ 0,00$ \\
Taxas de Importação & $\mathrm{R} \$ 601,18$ & $\mathrm{R} \$ 0,00$ \\
Total & $\mathrm{R} \$ 1.205,34$ & $\mathrm{R} \$ 129,90$ \\
\hline
\end{tabular}

\section{REFERÊNCIAS}

ALEXANDER, R. Amazon echo: o manual. São Paulo: Smart-home-system.org, 2018.

AMAZON. United States Patent and Trademark Office (USPTO). Disponível em https://pdfpiw.uspto.gov/.piw?Docid=09858719. Acesso em: 07/11/2020.

AMAZON ALEXA. The open source modular smart mirror platform. Disponível em https://developer.amazon.com/pt-BR/alexa. Acesso em: 18/09/2020.

BRASIL. Financiadora de Estudos e Pesquisas (FINEP). Disponível em http://www.finep.gov.br/noticias/todas-noticias/4446-kevin-ashton-entrevista-exclusiva-com-ocriador-do-termo-internet-das-coisas. Acesso em: 12/09/2020.

ESCUDEIRO, R. T. G. Specchio - espelho inteligente. Tese de Mestrado em Engenharia Informática, Instituto Politécnico de Tomar, Tomar, 2019.

HOSTMEDIA. Assistente Virtual Inteligente: Vá além do trivial. Disponível em https://www.hostmidia.com.br/blog/assistente-virtual-inteligente. Acesso em: 20/09/2020. 


\section{ISSN 2447-5378}

MAGICMIRROR ${ }^{2}$. The open source modular smart mirror platform. Disponível em https://docs.magicmirror.builders. Acesso em: 18/09/2020.

PAIVA, O. A.; MOREIRA, R. O. Raspberry Pi: dispositivo de 35 dólares para visualização de imagens DICOM. Revista de Radiologia Brasileira, 2014. v. 47, n. 2, p. 99-100.

PARTY MODULES. 3rd Party Modules. Disponível em https://github.com/MichMich/MagicMirror/wiki/3rd-Party-Modules. Acesso em: 18/09/2020.

PATENTES. Instituto Nacional da Propriedade Industrial (INPI). Disponível em https://www.gov.br/inpi/pt-br/servicos/perguntas-frequentes/patentes. Acesso em: 07/11/2020.

RASPBERRY. Raspberry Pi OS (anteriormente chamado de Raspbian). Disponível em https://www.raspberrypi.org/downloads/raspberry-pi-os/. Acesso em: 22/09/2020.

SAMSUNG. United States Patent and Trademark Office (USPTO). Disponível em https://pdfpiw.uspto.gov/.piw?Docid=D0830983. Acesso em: 07/11/2020.

SANTOS, S. Introdução à IOT - Desvendando a Internet das Coisas. Merano: [s.n.], 2018.

SILVA, C. C. V.; VIALICH, M. I. EXHIBEO - Espelho Inteligente para uso Doméstico. Trabalho de Conclusão de Curso de Engenharia de Computação. Universidade Tecnológica Federal do Paraná, Curitiba,2017.

THDESENVOLVEDORES. Desenvolvendo aplicações desktop com Electron. Disponível em https://medium.com/thdesenvolvedores/desenvolvendo-aplicacoes-desktop-electron-javascript350393d40d0. Acesso em: 22/09/2020. 